\title{
Ye shall Know them by their Verbs: How Gender Express their Opinion in Twitter
}

\author{
Madai Ramírez, Octavio Sánchez \\ UNAM, Grupo de Ingeniería Lingüística, \\ Mexico \\ MRamirezCi@iingen.unam.mx,oct_sanc@unam.mx
}

\begin{abstract}
It is commonly said that adjectives are a kind of word that people use for emitting their opinion. This is because this lexical category designates the qualities of an entity. However, there are different ways to express an explicit opinion besides the use of adjectives. People also can choose verbs, nouns, adverbs and even groups of words that have complex meaning, like idioms or other multi-word expressions. The main purpose of this work was to discover which gender prefers which lexical category to express their opinion. In this paper, we show how sentiment analysis can help to identify a gender. A corpus of tweets was compiled for this research. The tweets were classified into 'opinions' and 'no opinions'. Within the corpus, we looked at which grammatical category of word was bearing the holder's subjectivity. We found that women used $27.98 \%$ verbs while men $16.91 \%$, specifically psych verbs, in order to express their assessment.
\end{abstract}

Keywords: Author profiling, gender classification, opinion mining.

\section{Introduction}

Within social networks and various websites, million users express their opinion daily. Many of the opinions in these media remain anonymous. Knowing who wrote them might help for business intelligence or marketing as well as in security issues.

This paper is framed within forensic linguistics and opinion mining. The first discipline makes use of linguistic knowledge to solve legal problems such as plagiarism and authorship attribution. When the experts do not know who is the author of a text, they do author profiling, it means, they try to predict the age, gender and level of studies from the writer's style. In this work, we try to provide linguistic knowledge that could be used, in a future, to train a system for doing this prediction. We try to contribute to gender characterization by using an opinion mining analysis.

Opinion mining deals with subjective information, this is utterances that express appraisals, sentiments, or believes of people. It tries to find, extract and classify these expressions in text. For this work, we use the definition of opinion given by Liu [11]; this allowed us to tag them manually. 
In this case, the opinion mining analysis was used to find out the differences of how a gender express their assessment. The hypothesis was that gender of a person can be identified by analysing the words they use to emit their opinion. We used a corpus of tweets that was made for this research, we looked at which kind of word or phrase was bearing the holder's subjectivity and we found that women used $27.98 \%$ verbs while men $16.91 \%$, specifically psych verbs, in order to express their assessment.

In this work we provide information that can be used in automatic profiling. Instead of use all sentiment words, which imply high computational costs, we study which kind of subjective lexical category should be used and which other functional words has to be taken into consideration when profiling author by their emotions.

The rest of the paper is organised as follows. Section 2 will discuss past work related to this research. Section 3 is going to explain the methodology, which includes three subsections: how the corpus was made, how the corpus was labelled and the analysis. Section 4 talks about the results and finally, in section 5 we will present our conclusions and discuss future work.

\section{Related Work}

Since the middle of the last century, identifying the linguistic markers dependent on gender is a theme that has been exploited a lot. There has been papers like the one by Robin Lakoff [10] where she affirmed that women used more question tags and they asked questions when they really wanted to say a statement (rhetoric questions). Women also used more colours (e.g.: lavender), empty adjectives (e.g.: cute, divine, sweet, adorable) and weak insults when expressing themselves.

Subsequent studies [1,17] found that women prefer using pronouns (I, you, he, she, her, their, myself, yourself, herself), while men prefer the use of determinants (a, the, that, these) and quantifiers (one, two, more, some). Furthermore, Scheler [17] identified affirmation and negation words as female features and prepositions, articles and hyperlinks as male features. The use of hyperlinks means that men share more news, videos, pictures and so on.

Ana Janssen [7] notices that women use more third person pronouns and men make more use of first person pronouns. Those results contrast with Schartz [18] who states that women use more the first person pronouns and emotive words and psychological processes.

In Mexico, Rivera Vidal's dissertation [15] studies how genders express their opinion with adjectives. However, we believe that this is not the only kind of words which can express subjectivity, there are also adverbs, interjections, nouns, verbs and many idioms.

In opinion mining, Mohammad and Yang [12] researched about toward which emotion each gender orient their words within love letters, hate mail and suicide notes. Women lean more their words toward happy and sadness sentiments and men to trust and fear. 
In automatic author profiling, Patra et al.[13], Weren et al.[20] and Pimas et al.[14] used sentiments as a feature in order to classify gender and age. Besides, Patra et al. took into consideration pronouns, functional words and topics. With these features they got an accuracy of $56.83 \%$ for gender and $28.95 \%$ for age. Weren et al. considered the length of sentence, word and paragraph, and text readability. This means, how well written was the text, (repetition of vowels, punctuation, and misspelled words). Neither Patra nor Weren found that affective words can help to identify gender. Pimas et al. also used concreteness and syntactic information. For concreteness, they understand not abstract concepts. For sentimental features, they used SentiWordNet [4] in order to find the polarity of a word and they estimated the polarity of each tweet. As syntactic features they considered the word lenght and hashtags. They train their classifier with one type of text from social media, as tweets, blogs and others. They did the experiment twice and, the first time they got an accuracy of 0.5769 in the first set, and 0.0201 in the second one.

As it can be seen, the problem of profiling author from the subjective utterances they use, is far from being solved. We think there is a lack of linguistic knowledge on the area, therefore we try to offer this study in order to pave the way for automatic twitter author profiling based on the way they express their opinions.

\section{$3 \quad$ Methodology}

\subsection{Corpus}

We manually compiled a corpus of Twitter for this research because we wanted to control our demographic variables and it was the only way to guarantee that our data satisfy our requirements. There were a total of 40 participants: 20 men and 20 women; each one between the ages of 18 to 28 , with a college degree or that were studying university and everyone was born and had been living in Mexico City.

The last 50 tweets of each account were recollected and they had to be written in Spanish, and had to be original tweets, not just quotations or retweets.

\subsection{Labelling Corpus}

Each instance of the corpus was tagged with 'opinion' or 'non opinion'. "An explicit opinion is a subjective statement that gives a regular or comparative opinion" [11]. Therefore, we only considered a tweet like 'opinion' if it had the elements for a 'regular' or a 'comparative' opinion.

According to Wiebe [21], a regular opinion must have 4 elements:

1. Target: The target or topic of the private state, i.e., what speech event or private state is about.

2. Source: The person or entity that is expressing the private state, possibly the writer. 
3. Text anchor: a pointer of the span of texts that represents the speech event or explicit mention of a private state.

4. Polarity: The possible values are positive, negative, other or none.

With regard to the polarity, in this research, it was considered either positive or negative and in some cases we found that the message entails at the same time a positive and negative orientation, so we call those bipolar. E.g.:

(1) Me asusta lo mucho que me gusta Gossip Girl. ¡Maldita sea! (It scares me how much I like Gossip Girl. Dammit!)

(2) ¿Qué tan culposo es el gusto por Salón Victoria! Sí, los tengo en mi iTunes.

(How guilty is the pleasure for Salón Victoria! Yes, I have it in my iTunes.)

Examples appear to be paradoxical; but "they involve a dissociation of enunciating subject into an evaluator subject (with more or less objectified criteria) and a taster subject" [9]. That means, the people who wrote those tweets really like gossip girl and Salon Victoria, but the series and the band had some aspects that might be considered as dislikeable by the society, or even themselves.

In table 1 we show an example of a regular opinion extracted from the corpus:

(3) Breaking bad es una joya de serie ... desde la forma hasta el fondo. (Breaking bad is a jewel of series...from the form to the bottom).

Table 1. Example of a regular labelled opinion.

\begin{tabular}{|l|l|l|l|}
\hline Target & Source & Text anchor & Polarity \\
\hline Breaking bad & Hombre $(\operatorname{man})$ & una joya de serie( a jewel of serie) & Positivo(Positive) \\
\hline
\end{tabular}

A comparative opinion "expresses a relation of similarities and differences between two or more entities and/or a preference of the opinion holder based on some shared aspects of entities" [8]. According to [11] comparative opinion must have:

- E1: entity 1

- E2: entity 2

- A: aspects

- PE: which entity the opinion holder prefers

- H: opinion holder.

As you can see in this schema, the polarity is not a feature because "this type of opinions are not directly positive or negative. Instead, the entities are being compared and ordered according to the aspects they share between them. This is, they express a preference for one or more entities" [11]. However, we designated one polarity to comparative opinions with respect to E1. In 2 there is an example of comparative opinions and how we labelled them: 
(4) Honestamente no hay mejor voz femenina mexicana que la de ANA GABRIEL para cantar el Cielito Lindo

(Honestly there is no better feminine voice than Ana Gabriel for singing Cielito Lindo)

Table 2. Example of a comparative labelled opinion.

\begin{tabular}{|l|l|l|l|l|}
\hline E1 & E2 & holder & aspect & polarity \\
\hline Ana Gabriel & $\begin{array}{l}\text { el resto de las cantantes } \\
\text { femeninas mexicanas } \\
\text { (the other mexican singers) }\end{array}$ & hombre & $\begin{array}{l}\text { no hay mejor } \\
\text { voz femenina mexicana } \\
\text { (there is no better } \\
\text { mexican feminine voice) }\end{array}$ & (positive) \\
\hline
\end{tabular}

In addition to the above labels, we tagged comparative opinions into the different kinds. It was considered that there are two types of comparative opinions: gradable and non gradable. Nevertheless, non gradable opinions in spite of comparing two or more objects, they do not rank them like gradable opinions do [11], therefore it could be difficult to identify an opinion and we did not classify them. Gradable opinions are subclassified [8] into:

- Non equal gradable relations of the type greater or less than that express a total ordering of some entities with regard to certain features. This type also includes user preferences.

- Equative: relations of type equal to that state to two entities as equal with respect to some features.

- Superlative: Relations of the type greater or less than all others that rank an entity over all others.

On the other hand, "non opinion" does not have the requirements previously mentioned for regular or comparative opinion like target, entity, sentiment, polarity, and so on.

It is important to say that some tweets had more than one opinion and they had to be separated, although it is the same subject but it is considered a different aspect of the target and was given another polarity. Then, every opinion was classified in themes.

\subsection{Analysis}

Once we had the corpus compiled and labelled, we made a linguistic analysis of the elements. In order to achieve this, the 'text anchor' was manually classified into one lexical category such as noun, verb, adjective, interjection and adverb.

We labeled axiological and affective adjectives. The former do an evaluation between 'good' and 'bad', while the latter take into consideration an object's property and a subject's emotional reaction [9]. Within this adjectives 
are evaluative (good, bad, ugly, beautiful) and adjectives of skills and human predisposition, which include emotional attitudes (sensitive, friendly, cordial), intellectual (intelligent, capable, sabio), and passions and primary disposal (nervous, aggressive) [2].

According to [9], there are occasionally subjective verbs and inherently subjective verbs. The first one evaluates the object of the process and the second ones evaluate the process and one of the agents. Among the first, there are psych verbs, which one express an appraisal and an emotional reaction at the same time (e.g. like, love, hate, appreciate), and say verbs where "the emotional state of $\mathrm{x}$ is explicit in a verbal behavior" (e.g. regret, blame, deplore, praise). Among the inherently subjective verbs, there are stink, offend, infringe, deserve, failed.

Sometimes it was found participles and gerunds outside verbal periphrases (which were tagged into verbs), in that case, participles were labelled as adjectives and gerund as verbs. Many nouns that we labelled are derived from verbs and adjectives, such as love, beauty, etc.

Interjections, like jAy!, ibah!, ibravo!, iguau!, ;Aj!, ipuaj!, communicates feelings and impressions, they show various emotional reactions. This means that they can express surprise, assent or rejection, among other moods [3].

Moreover, it seemed appropriate to label different kind of multi-word expressions such as idioms and collocations like zeso qué? (So what!)that reflected sentiments. Most MWE found in the corpus appeared as so in the online DRAE (Diccionario de la Real Academia Española), for example: ¡Maldita sea! (Dammit!), Valer la pena (worth it). The rest has a similar structure and meaning.

The modifiers and syntax function were also analysed. The modifiers can increase or decrease the intensity of an opinion. We considered modifiers adverbs as muy (very), demasiado (extremely), poco (few/little), tremendamente (monstrously), increíblemente (unbelievably) [2]. Their syntax function can be attribution or predication. Attributive function happens when the adjective influence directly on the noun [16].E.g.:

(5) La hermosa casa donde solía vivir.

(The beautiful house where I used to live).

With regard to predication, the adjective is attached with the noun by and explicit or implied verbal copulation [16]. E.g.:

(6) La casa era hermosa.

(The house was beautiful)

Sometimes the adjective can function as a noun, this is called nominalization and it is made with an article (el, la, los, las, lo) plus and adjective [16].E.g.:

(7) Hay que resolver lo difícil.

(You have to solve the difficult [things]).

There is another adjective function which is not syntactical but it is discursive: vocative. It is like "interjections but, they are isolated words from the rest 
of the sentence by commas, reinforcement of intensity and special intonation in spoken language and written language, by commas. They belong to the appellate function in language" [5]. E.g.:

(8) La neta me dan muchísimo oso las personas que aprovechan los disfraces de jalouin para mostrar su cuerpo y verse "súper sexies”. ¡Ridículos!.

(It is shameful when the people take advantage of Halloween costumes so that they can show their body and be 'super sexy'. Ridiculous!)

Finally, a frequency count of any single label was done, thus a statistical test called chi-squared was executed so we could evaluate the dependence of the variables. When you got p-value under 0.05 , you can accept that there are dependence between the variables [6].

\section{Results}

Table 3 shows the quantity of 'opinions' and 'no opinions'. As it can be seen, the sum of both it is not 1000 because, as it was said before, some tweets had more than one opinion. In this case, women shared $4.08 \%$ more opinions, but the p-value of chi-square was 0.5098 , which means there is no dependency between the variables gender and opinion.

Table 3. Opinions.

\begin{tabular}{|l|l|l|l|l|}
\hline & men & & women & \\
\hline opinion & 686 & $61.19 \%$ & 720 & $65.27 \%$ \\
no opinion & 435 & $38.80 \%$ & 383 & $34.72 \%$ \\
\hline
\end{tabular}

Figures 1 and 2 present the most common topics of the opinions, those that exceed $2 \%$. In both cases, the most common theme was 'person', with $16 \%$ and $19 \%$ respectively. Men talked more about 'politics', 'sports' and 'films'. 'Other' encompasses topics with percentage of occurrence less than $2 \%$ like 'climate ',' places', 'galaxy', etc. In this case, women used more and varied topics.

We also compared the polarity of the opinion, table 4 show the differences. In the corpus, women's sentiments were more positive than men's sentiments, $3.69 \%$. Meanwhile, men's sentiments were more negative than women's sentiments, $3.93 \%$. The p-value result was 0.3327 , that means the variables, gender and polarity are independent.

The type of opinions: 'regular' and 'comparative', are shown in table 5. The results were not very different. For 'regular', 89.16\% were feminine and $88.19 \%$, masculine. For 'comparative', $10.83 \%$ were feminine and $11.80 \%$ masculine.

Table 6 shows the amount of type of comparative opinions. We did not find a big difference between genders.

Table 7 shows the lexical categories and phrases that was bearing the holder's subjectivity and which is their distribution inside our corpus. You can note that 
Madai Ramírez, Octavio Sánchez

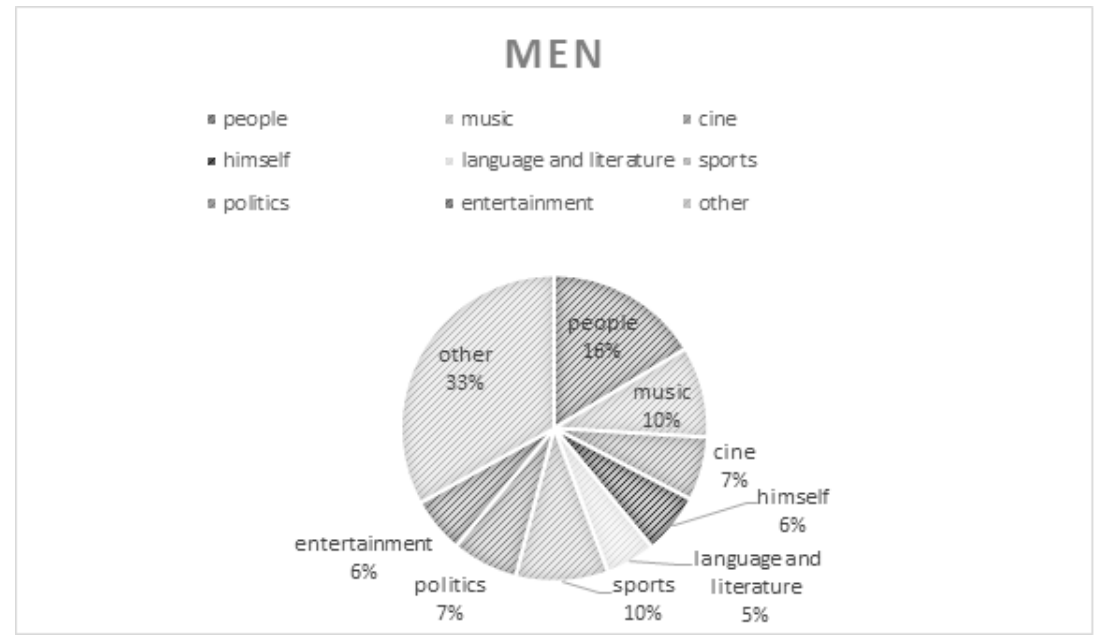

Fig. 1. Men's topic.

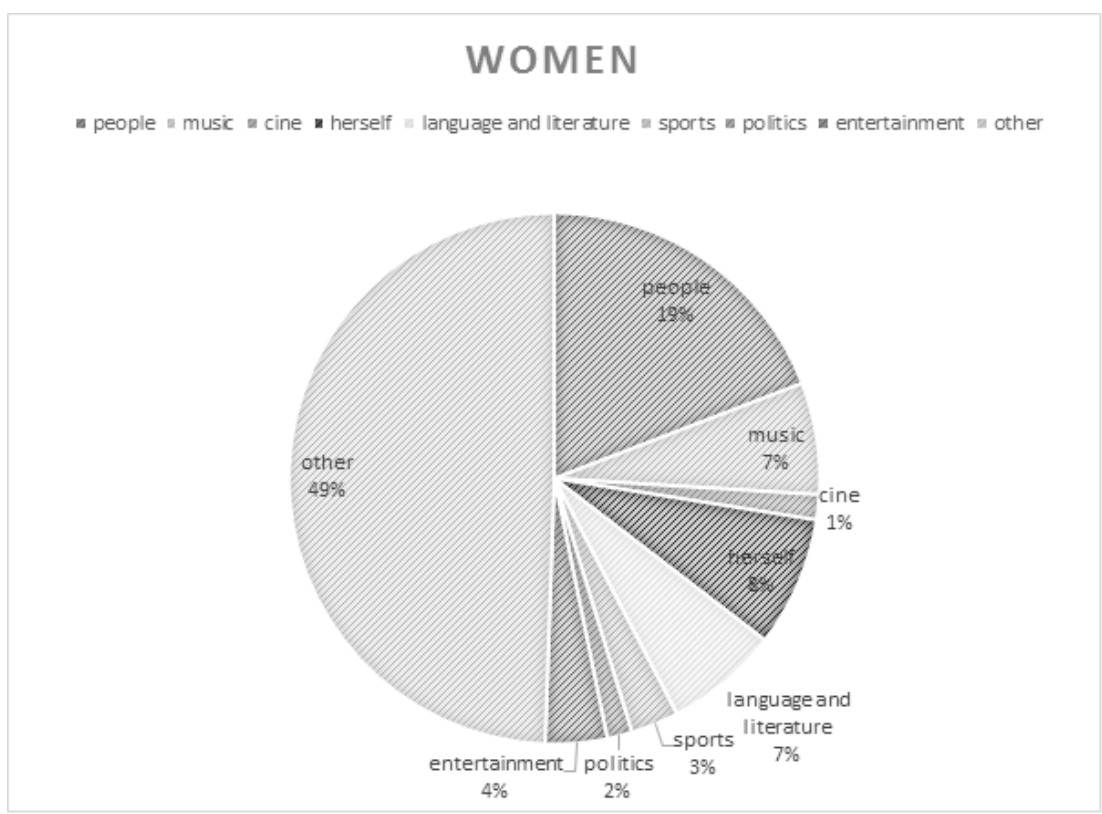

Fig. 2. Women's topics.

adjectives are the most useful lexical category, those represents almost the fifty percent of opinion words in the corpus. And men use more than women, almost $5 \%$ more. Nouns are more used by men (3.61\% more) and verbs are more used by women (11.07\%).The rest of categories do not exceed $1 \%$ of difference. 
Table 4. Opinion polarity.

\begin{tabular}{|l|l|l|l|l|}
\hline & men & & women & \\
\hline positive & 331 & $48.25 \%$ & 374 & $51.94 \%$ \\
negative & 347 & $50.58 \%$ & 336 & $46.65 \%$ \\
bipolar & 8 & $1.16 \%$ & 10 & $1.38 \%$ \\
total & 686 & & 720 & \\
\hline
\end{tabular}

Table 5. Types of opinion.

\begin{tabular}{|l|l|l|l|l|}
\hline & men & & women & \\
\hline regular opinions & 605 & $88.19 \%$ & 642 & $89.16 \%$ \\
comparative opinions & 81 & $11.80 \%$ & 78 & $10.83 \%$ \\
total & 686 & & 720 & \\
\hline
\end{tabular}

Table 6. Types of comparative opinions.

\begin{tabular}{|l|l|l|l|l|}
\hline & men & & women & \\
\hline superlative & 56 & $69.13 \%$ & 60 & $76.92 \%$ \\
non equal gradable & 22 & $27.15 \%$ & 17 & $21.79 \%$ \\
equative & 3 & $3.70 \%$ & 1 & $1.28 \%$ \\
total & 81 & & 78 & \\
\hline
\end{tabular}

Table 7. Lexical category.

\begin{tabular}{|l|l|l|l|l|}
\hline & men & & women & \\
\hline nouns & 147 & $18.01 \%$ & 122 & $14.40 \%$ \\
adjectives & 433 & $53.06 \%$ & 407 & $48.05 \%$ \\
verbs & 138 & $16.91 \%$ & 237 & $27.98 \%$ \\
interjections & 16 & $1.96 \%$ & 23 & $2.71 \%$ \\
adverbs & 21 & $2.57 \%$ & 12 & $1.41 \%$ \\
idioms & 32 & $3.92 \%$ & 41 & $4.84 \%$ \\
other phrases & 29 & $3.55 \%$ & 28 & $3.30 \%$ \\
total & 816 & & 847 & \\
\hline
\end{tabular}

Because verbs are the best candidates in order to differentiate gender, we decided to look into it. We observed that psych verbs are the most common kind of verbs. Psych verbs are verbs that "denote emotional states as fear, liking and annoyance. And that implicate two arguments: an experimenter, which in this case refers to the person that experiences the emotion indicated by the verb, and a theme, which refers to the entity that relates with the emotion" [19]. We separated the verbs into 'psych' and 'no psych'. Figure 3 illustrates that. The darker colour shows that women used the double psych verbs than men.

Table 8 shows most common psych verbs. Note that women use more than double than men. We did a chi-squared test and we got $4.061 \mathrm{e}-06$, it means the variables are dependent one from other.

Adjectives are the most common category for expressing opinion. Because of this, we decided to analyse the function, which is in the table 9 , in order to see the 
Madai Ramírez, Octavio Sánchez

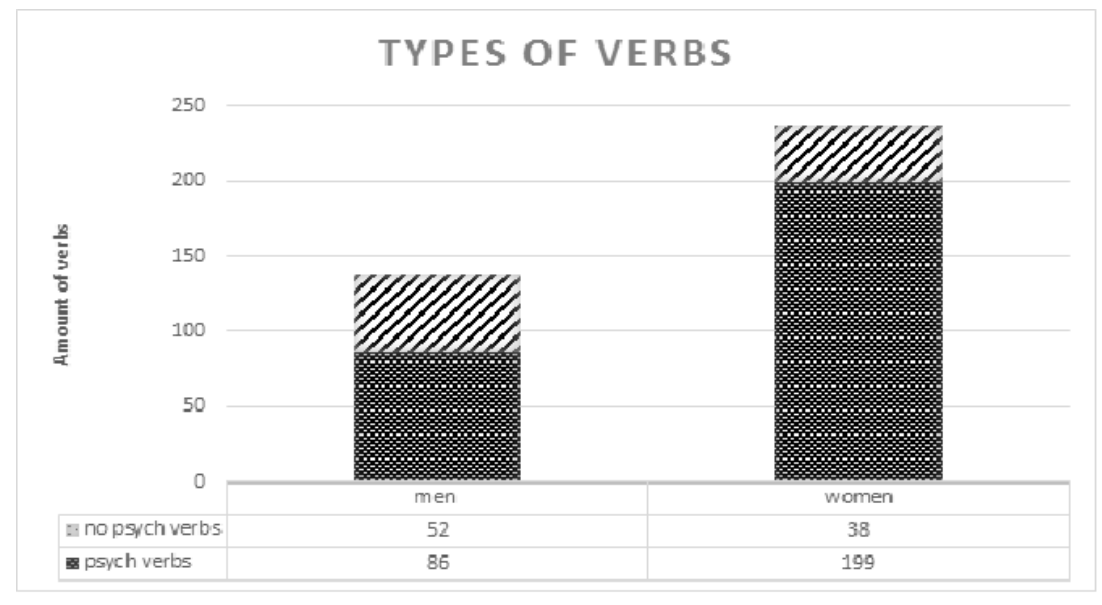

Fig. 3. Type of verbs.

Table 8. The most common psych verbs.

\begin{tabular}{|l|l|l|}
\hline verbs & men & women \\
\hline amar(to love) & 6 & 39 \\
gustar(to like) & 12 & 26 \\
querer(to want) & 11 & 22 \\
adorar(to adore) & 0 & 12 \\
extrañar(to miss) & 8 & 16 \\
odiar(to hate) & 4 & 20 \\
\hline
\end{tabular}

differences in use between genders. Men employed more adjectives in attributive function $(50.57 \%)$ while women, more in predicative function (45.94\%). We did chi-squared. The p-value was 0.05241 . That means, there is no dependence.

Table 9. Adjectives function.

\begin{tabular}{|l|l|l|l|l|}
\hline & men & & women & \\
\hline attributive & 219 & $50.57 \%$ & 172 & $42.26 \%$ \\
predicative & 159 & $36.72 \%$ & 187 & $45.94 \%$ \\
nominalization & 42 & $9.69 \%$ & 38 & $9.33 \%$ \\
vocative & 13 & $3.00 \%$ & 10 & $2.45 \%$ \\
total & 433 & & 407 & \\
\hline
\end{tabular}

With regard to adjectives modifiers, 122 were masculine and 147 , feminine. In other words, girls modified their adjectives $33.16 \%$, when boys did it just $26.09 \%$. 


\section{Conclusion and Future Work}

In this work we produced a small Twitter corpus in order to be manually analised. It was done manually because we were interested in getting precise features of how men and women utter opinions. We produced linguistic knowledge that can be used later by forensic experts as well as automatic author profiling systems.

The results showed that men and women utter opinions in similar proportions in Twitter. It was found some differences in the issues that they review; however the polarity or the types of opinions that they used is not a distinctive feature.

Adjectives are the kind of word most productive for expressing opinions, but the meaningful difference consists in women preferring predicative function, while men preferred attributive function.

In addition, verbs are the kind of words that women had rather for expressing their opinion, specifically with psych verbs.

For future work, it will be researched if the results shown can also help to identify gender but with different age and scholar level. Besides it will be explored gender subjectivity and age group in another kind of private states like desires and beliefs.

Acknowledgements. This research was funded by a PAPIIT project called "Distributional semantics approaches for opinion mining" with code IN403016 and to the Consejo Nacional de Ciencia y Tecnología (CoNaCyT) for the support given through grant 387405 and project CB2012/178248. We also want to thank Red Temática de Tecnologías del Lenguaje de CoNaCyT

\section{References}

1. Argomon, S., Koppel, M., Fine, J., Shimoni, A.: Gender, genre, and writing style in formal written text. Text 23, 321-345 (2003)

2. Demonte, V., Bosque, I.: Gramática descriptiva de la lengua española. Espasa Calpe (1999)

3. Española, R.A.: Manual de la nueva gramática de la lengua española. Madrid. Asociación de Academias de la Lengua Española (2010)

4. Esuli, A., Sebastiani, F.: Sentiwordnet: A publicly available lexical resource for opinion mining. In: Proceedings of LREC. vol. 6, pp. 417-422. Citeseer (2006)

5. Gili Gaya, S.: Curso superior de sintaxis española. Bibliograf (1943)

6. Gries, S.T.: Statistics for linguistics with R: a practical introduction. Walter de Gruyter (2013)

7. Janssen, A., Murachver, T.: The role of gender in new zealand literature comparisons across periods and styles of writing. Journal of Language and Social Psychology 23(2), 180-203 (2004)

8. Jindal, N., Liu, B.: Mining comparative sentences and relations. In: AAAI. vol. 22, pp. 1331-1336 (2006)

9. Kerbrat-Orecchioni, C.: Los subjetivemas "afectivo" y "evaluativo"; axiologización y modalización. In: La enunciación de la subjetividad en el lenguaje (1086)

10. Lakoff, R.: Language and woman's place. Language in society 2(01), 45-79 (1973) 
11. Liu, B.: Sentiment analysis and opinion mining. Synthesis lectures on human language technologies 5(1), 1-167 (2012)

12. Mohammad, S.M., Yang, T.W.: Tracking sentiment in mail: how genders differ on emotional axes. In: Proceedings of the 2nd workshop on computational approaches to subjectivity and sentiment analysis (acl-hlt 2011. pp. 70-79 (2011)

13. Patra, B.G., Banerjee, S., Das, D., Saikh, T., Bandyopadhyay, S.: Automatic author profiling based on linguistic and stylistic features. Notebook for PAN at CLEF (2013)

14. Pimas, O., Rexha, A., Kröll, M., Kern, R.: Profiling microblog authors using concreteness and sentiment (2016)

15. Rivera Vidal, M.A.: Sociolingüística de los adjetivos calificativos en un corpus de español mexicano. Master's thesis, Universidad Nacional Autónoma de México (UNAM) (2015)

16. Romero Gualda, M.V.: El nombre: sustantivo y adjetivo. Arco (1989)

17. Schler, J., Koppel, M., Argamon, S., Pennebaker, J.W.: Effects of age and gender on blogging. In: AAAI Spring Symposium: Computational Approaches to Analyzing Weblogs. vol. 6, pp. 199-205 (2006)

18. Schwartz, H.A., Eichstaedt, J.C., Kern, M.L., Dziurzynski, L., Ramones, S.M., Agrawal, M., Shah, A., Kosinski, M., Stillwell, D., Seligman, M.E., et al.: Personality, gender, and age in the language of social media: The open-vocabulary approach. PloS one 8(9), e73791 (2013)

19. Vroon, S.: ¿ le está gustando la música o lo molesta el ruido? una investigación sobre el aspecto semántico de los verbos psicológicos \& su uso con las formas de los pronombres átonos y en las perífrasis de gerundio. (2006)

20. Weren, E.R., Kauer, A.U., Mizusaki, L., Moreira, V.P., de Oliveira, J.P.M., Wives, L.K.: Examining multiple features for author profiling. Journal of Information and Data Management 5(3), 266 (2014)

21. Wiebe, J., Wilson, T., Cardie, C.: Annotating expressions of opinions and emotions in language. Language resources and evaluation 39(2-3), 165-210 (2005) 